\title{
Autoscopia de uma professora em formação continuada para a aprendizagem da filogenia
}

Autoscopy of a teacher in continued training for the learning of phylogeny

\author{
Verônica Klepka ${ }^{1}$ \\ Maria Julia Corazza ${ }^{2}$
}

\section{Resumo}

O trabalho tem como foco de estudo a formação continuada reflexiva de uma professora de Ciências e Biologia durante um curso voltado a aprendizagem da Sistemática Filogenética. A reflexão ocorreu posteriormente a uma aula simulada, resultado do comando solicitado aos participantes do curso sobre como trabalhariam a classificação biológica com sua turma. O objetivo foi identificar na autoscopia da professora indícios da reflexão caracterizada por Schön. Observamos que as reflexões retrospectivas sobre a reflexão para a ação foram mais significativas, pois demonstraram com clareza os momentos da reflexão-na-ação de planejamento da aula, momento individual que demonstrou ser de grande importância para a professora. Os pressupostos epistemológicos com relação à reflexão na e sobre a prática docente nos permitiram observar as aprendizagens da professora, seu desenvolvimento e suas escolhas, bem como as dificuldades encontradas antes e depois do exercício da prática docente quanto ao conteúdo de sistemática filogenética.

Palavras chave: ensino de ciências; professor reflexivo; autoscopia; formação continuada.

\section{Abstract}

The work has as a study focus the continuous reflective formation of a professor of Sciences and Biology during a course aimed at learning the Systematic Philogenetic. The reflection occurred later to a simulated class, result of the command requested to the participants of the course on how they would work the biological classification with its class. The objective was to identify in the autoscopy of the teacher indications of the reflection characterized by Schön. We observed that the retrospective reflections on reflection for action were more significant, since they clearly demonstrated the moments of reflection-in-action of lesson planning, an individual moment that proved to be of great importance to the teacher. The epistemological assumptions regarding reflection in and about teaching practice allowed us to observe the teacher's learning, their development and their choices, as well as the difficulties encountered before and after the practice of the teaching practice regarding the content of systematic phylogenetic.

Keywords: science teaching; reflective professor; autoscopy; continuing education.

\footnotetext{
${ }^{1}$ Universidade Federal do Triângulo Mineiro | veronicaklepka@gmail.com

${ }^{2}$ Universidade Estadual de Maringá | mjcorazza@gmail.com
} 


\section{Introdução}

Este artigo resulta de uma tese de doutorado que teve o propósito de investigar a influência das mudanças epistemológicas contidas na História da Classificação Biológica na prática pedagógica de professores de Ciências e de Biologia. A pesquisa surgiu de um movimento pelo abandono das clássicas categorias taxonômicas herdadas de Lineu e sua substituição pelo método evolutivo (AMORIM, 2008), o Sistemático Filogenético, nascido na década de 1960 (AMORIM, 2002), constatado na literatura e defendido no ensino de Ciências e Biologia desde os anos 2000.

Nestas pesquisas, a evolução é defendida como eixo integrador do ensino de conteúdos biológicos visando romper com a classificação estritamente morfológica e sem sentido, e o ensino fragmentado de Ciências e de Biologia (SANTOS; CALOR, 2007; LOPES; VASCONCELOS, 2012). Desde então, muitas pesquisas têm acompanhado a inserção da Sistemática Filogenética nos livros didáticos de Ciências e de Biologia (CORDEIRO; MORINI, 2017); na formação inicial e continuada de professores (RODARTE; SANTOS, 2016); e nas diversas etapas de ensino e aprendizagem (LIPORINI, 2016). Estes mesmos trabalhos observaram a ausência ou fragilidade da perspectiva filogenética em materiais didáticos, o despreparo dos professores para articular a sistemática filogenética aos conteúdos biológicos e, consequentemente, a necessidade de formação continuada para professores de modo a suprir possíveis lacunas formativas sobre o tema; além das dificuldades de aprendizagem por parte dos alunos.

O fato de não haver estudos que apontassem a potencialidade de cursos de formação continuada para resolver as fragilidades formativas constatadas pelas referidas pesquisas (RODARTE; SANTOS, 2016), serviu como incentivo para o planejamento e execução de um Curso de Formação Continuada que fornecesse elementos teóricos e práticos acerca da Sistemática Filogenética, possibilitando sua aplicação no ensino de Ciências e de Biologia por meio de práticas, materiais e linguagem acessíveis. Assim, o curso proposto na pesquisa de doutorado teve como objetivo propiciar o conhecimento acerca das mudanças ocorridas na classificação dos seres vivos e a aprendizagem sobre como construir e interpretar árvores filogenéticas, de modo a contribuir com a prática pedagógica dos professores de Ciências e de Biologia.

O planejamento e execução do referido curso se deu a partir da parceria interdisciplinar da primeira autora deste artigo com um professor doutor, especialista em ecologia, taxonomia e sistemática de peixes de água doce, atuante também na formação de professores do município de Uberaba - Minas Gerais. Em cada encontro do curso de 32 horas uma temática foi discutida. Também foram realizadas atividades práticas, simulações, investigações e discussões de como inserir a filogenética no ensino.

Os conteúdos que compuseram os encontros e a forma de trabalhá-los foram planejados conjuntamente com o professor convidado e contou com a inclusão da História da Ciência e de discussões dessa natureza voltadas ao ensino. Além disso, foi consenso de que não haveria sentido um professor aprender a trabalhar com árvores filogenéticas sem saber como são construídas, como são interpretadas e, antes disso, que conhecimentos são mobilizados para alcançar todo potencial interpretativo de um cladograma. Por esse motivo, no curso, foram resgatados os conhecimentos biológicos básicos de ecologia, evolução e genética. Além disso, foram introduzidos e trabalhados os princípios do método sistemático filogenético entre outros conteúdos conforme podem ser observados com detalhes em KLEPKA 1 (2017). 
Neste artigo, apresentamos parte dos dados provenientes desta pesquisa na qual as ações pedagógicas voltavam-se à constituição dos dados durante o Curso de Formação Continuada. Em específico, analisamos as respostas de uma das participantes à solicitação feita para que construíssem e apresentassem uma proposta de aula, conforme comando a seguir:

Pensando em: Como você trabalharia a classificação biológica com sua turma? Proponha uma pequena aula (máx. 15 minutos) de modo a explorar um aspecto, conteúdo ou grupo biológico de seu interesse. Não se esqueça de que a proposta da aula é ensinar a classificação. O método, abordagem e conteúdo a serem empregados são de sua inteira escolha e devem estar descritos e justificados no plano de aula a ser entregue no momento da apresentação contemplando também o público alvo (série) e os objetivos (KLEPKA, 2017, p.186).

É importante observar que o comando manteve-se livre para que pudéssemos avaliar se o curso contribuiu com a prática pedagógica dos professores. Em outras palavras, tendo conhecido, aprendido e exercitado em grupo e individualmente a classificação dos seres vivos em uma perspectiva sistemática filogenética, acreditávamos que os professores conduziriam suas propostas nesta abordagem, o que não se concretizou. Dos cinco participantes presentes, apenas três apresentaram propostas de aula concretas mediante plano de aula. Os outros dois apenas descreveram verbalmente como fariam a aula. $\bigcirc$ uso da taxonomia tradicional pautada em cinco reinos foi a opção proposta por três dos participantes, e apenas dois assumiram a possibilidade de uso da árvore filogenética, sendo que um deles simulou como faria essa aula. É sobre a autorreflexão dessa participante, posterior a sua aula simulada, que conduziremos nossa análise neste trabalho.

\section{As mudanças históricas e epistemológicas no ensino da classificação biológica no século XXI.}

Na História da Taxonomia pelo menos três momentos podem ser importantes para esta disciplina, a saber: i) a criação de um método de classificação por Lineu; ii) a publicação da Teoria da Evolução; e, iii) a reforma metodológica visando uma área sistemática no século XX (KLEPKA, 2017). Consequentemente, uma série de mudanças históricas e epistemológicas fez parte desse contexto. O rompimento com lógicas escolásticas pelo método investigativo dos seres vivos visando à construção de uma classificação natural, que estabelece relações entre as espécies com Lineu; a explicação de fatores de diversificação das espécies em detrimento de uma criação divina com Darwin e Wallace; a busca por modos de investigação para além dos descritivos; a consideração das dimensões temporais e espaciais na análise das mudanças biológicas, entre outros tantos aspectos, demonstram que a natureza do conhecimento empregado pelos naturalistas e biólogos alterou-se consideravelmente ao longo do tempo.

Embora essas mudanças não tenham rompido totalmente com visões anteriores acerca dos fenômenos biológicos, como a dicotomização estática dos seres (por exemplo, voa versus não voa), mas tenham grande significado para o modo pelo qual trabalham atualmente as Ciências Biológicas, parte delas ainda não foi refletida no modo de compreender as Ciências Biológicas nos sistemas de ensino superior e básico brasileiro. 
Ensinamos no Brasil desde o século XX por vezes com noções biológicas anteriores a Lineu e, por outras, com uma amálgama delas. Assim, quando se adota a perspectiva pragmática ou utilitária para se classificar organismos biológicos, está se remetendo a uma lógica classificatória anterior a Lineu, por exemplo.

No Decreto n.19.800 de 1931 percebemos de onde vem nossa herança de trabalhar com as características gerais no ensino. Segundo ele, o ensino deveria priorizar as noções de célula, de habitat, de alimentação etc., ou seja, o estudo dos "caracteres gerais da espécie e, em particular, aqueles que servem de critério à classificação" (BRASIL. Decreto no 19.800, 1931, p.12121). Assim, considerando que essa classificação se dava por método comparativo e a ênfase nos animais em detrimento de plantas, explica-se por que as classes dos animais são ênfases do Ensino de Ciências e Biologia até os dias atuais em livros didáticos. Takeuchi (2017, p. 76) inclusive chama atenção desse fato no livro didático da época, no qual essa forma de classificação em "classes de animais (invertebrados, moluscos, articulados, radiados, protozoários) [...] tenha ganhado relevância e se mantido como conteúdo de ensino".

Desse modo, a classificação nas primeiras décadas do século XX foi ensinada como formas de agrupamento sem a menção ao conhecimento evolutivo e por meio de uma amálgama de sistemas classificatórios há muito abandonados por suas separações meramente utilitárias ou medicinais, ou seja, anteriores a Lineu. Não havendo qualquer menção às categorias taxonômicas de filo, ordem, classe, gênero ou mesmo espécie.

O novo PCN voltado para o ensino médio (PCNEM +, 2002) foi o documento que deu grande visibilidade não apenas à ideia de evolução como conhecimento, como à grande área de conhecimento: Evolução. O documento faz uma crítica à ênfase na classificação pautada na anatomia e fisiologia em que "os animais (e os vegetais) são abstraídos de seus ambientes e as interações que estabelecem com outros seres vivos, geralmente, são ignoradas" (PCNEM +, 2002, p.35). Assim, a classificação passa a ser reconhecida para compreender a biodiversidade e as "categorias taxonômicas reconhecidas atualmente" (PCNEM +, 2002, p.48) são apontadas como de necessário conhecimento ao aluno. Nesse mesmo documento, aponta-se como objetivo de ensino-aprendizagem tanto o trabalho na perspectiva dos cinco reinos, como na da filogenética: "Reconhecer as principais características de representantes de cada um dos cinco reinos, identificando especificidades relacionadas às condições ambientais", e, "Construir árvores filogenéticas para representar relações de parentesco entre diversos seres vivos" (PCNEM +, 2002, p. 48 - destaque nosso). Ainda, "Traçar as grandes linhas da evolução dos seres vivos a partir da análise de árvores filogenéticas" e "Construir a árvore filogenética dos hominídeos, baseando-se em dados recentes sobre os ancestrais do ser humano" (PCNEM +, 2002, p. 51 - destaques nosso). No entanto, em nenhum momento do documento se menciona o método que permitirá, aos professores e alunos, analisar e construir essas árvores, a Sistemática Filogenética.

A Sistemática Filogenética é um método das áreas taxonômicas e sistemáticas, construída sobre as bases da evolução. Ela mobiliza característica em diversos níveis, sejam anatômicos, fisiológicos, ecológicos, genéticos, entre outros. E o teste das relações entre os indivíduos com base nessas características é que gera a representação. Portanto, uma árvore filogenética não é única, muito menos neutra. Ela é a representação de um pesquisador, segundo as hipóteses e dados que testou. Assim, ao apresentar "apenas" cladogramas ou árvores filogenéticas para serem interpretadas no ensino, como figuras 
neutras, imutáveis e descontextualizadas, cai-se no mesmo reducionismo que tentamos combater há décadas na ciência.

Defendemos que a Sistemática Filogenética deva ser ensinada como um método de compreender o mundo, que é mutável, individual e que representa apenas uma hipótese do parentesco evolutivo entre as espécies. Defendemos, portanto, que professores sejam ensinados a construir árvores filogenéticas simples, e a interpretá-las com as ferramentas evolutivas e conceitos do próprio método. Por fim, defendemos que a Sistemática Filogenética na Educação Básica seja o método que integre o ensino de diversos conteúdos desfragmentando o ensino e trazendo a evolução como argumento explicativo dos fenômenos.

\section{A autoscopia como recurso discursivo de reflexão na e sobre a prática em contextos de formação continuada.}

O papel da linguagem como reflexo do pensamento é de grande relevância nos processos de ensino e aprendizagem. Nesses processos, "quanto mais falo e expresso minhas ideias, tanto melhor as formulo no interior do meu pensamento" (SOUZA, 1994, p. 112). Desse modo, a autoscopia é assumida neste trabalho como algo para além de uma técnica de pesquisa, trata-se de um mecanismo pelo qual o sujeito em aprendizagem pode dar novos sentidos e significados no presente às suas ações passadas e futuras. Justifica-se, assim, a interpretação que adotamos para a autoscopia como uma variação do uso convencional.

Sadalla e Larocca (2004, p. 421) descrevem a autoscopia como um procedimento aliado à videogravação para a "confrontação da imagem de si na tela". Uma vez filmado em uma determinada ação, o sujeito pode rever suas ações, suscitando autorreflexões sobre sua prática.

A técnica tem sido apontada como vantajosa para pesquisas em sala de aula, uma vez que permite ao pesquisador uma compreensão mais profunda sobre o fenômeno de interesse em comparação com outras formas de pesquisa e a superficialidade que apresentam ao revisitar o fenômeno (SADALLA; LAROCCA, 2004). Portanto, o procedimento de autoscopia tem passado por adaptações em algumas pesquisas, a destacar a de Arrigo, Lorencini Jr. e Broietti (2017), na qual a técnica foi utilizada em conjunto com os processos de reflexão sobre a ação e reflexão sobre a reflexão- na- ação na formação de licenciandos.

Jonh Dewey já dizia que a reflexão é uma forma especializada de se pensar, pois lança luz sobre ações e as consequências delas, evidenciando os motivos para executá-las. Esta ideia é complementada por Isabel Alarcão ao explicar que o pensamento reflexivo é diferente de uma ação por impulso, já que a reflexão tem base no pensamento, na intencionalidade da ação e no questionamento dessa ação. Sendo assim, corresponde a um processo lógico e psicológico. Disso decorre que o pensamento reflexivo, na formação de professores, vem romper com a concepção de uma profissão restrita às técnicas e competências, propondo a reflexão como estruturadora da ação docente (ALARCÃO, 1994).

Os professores desempenham um importante papel na produção e estruturação do conhecimento pedagógico porque refletem, de uma forma situada, na e sobre a interação que se gera entre o conhecimento científico [...] e a sua aquisição pelo aluno, refletem na e sobre a interação 
entre a pessoa do professor e a pessoa do aluno, entre a instituição escola e a sociedade em geral. Desta forma têm um papel ativo na educação e não um papel meramente técnico que se reduza à execução de normas e receitas ou à aplicação de teorias exteriores à sua própria comunidade profissional (ALARCÃO, 1994, p. 4- tradução nossa).

Para Donald A. Schön essa reflexão, mencionada por Alarcão, entre professores e alunos em situações de ensino pode ocorrer em dois momentos distintos: na ação, que é o ato de se pensar na prática, no momento em que a executa, e sobre a ação, correspondendo ao pensar retrospectivamente sobre a ação executada (SCHÖN, 2000). Reconhecendo que essa reflexão não se esgota na atuação docente, mas reverbera em sua identidade profissional, em seu papel na sociedade (ALARCÃO, 1994), entre outras dimensões, especificamente na formação docente, inicial e/ou continuada, o pensamento reflexivo torna-se profícuo para compreender o porquê o professor toma determinadas atitudes em relação ao planejamento e ensino de um conteúdo e sua própria relação com este conteúdo. A autorreflexão, ao ser expressa de forma escrita ou oral, constitui-se em objeto de análise.

Nesse sentido, faz-se necessário ouvir o docente em formação para compreender o que e como ele pensa, como esse pensamento reflete em seu planejamento e em sua prática. Para Schön (2000), o fato de procurar compreender problemas relacionados à consciência prática (que ele chamou de parte mais baixa ou pantanosa da topografia irregular da prática profissional) permite alcançar respostas que não são únicas, canônicas, pois a situação é sempre incerta e imersa em conflitos e valores. Contudo, o autor ressalta que são justamente esses problemas que se tornam centrais à prática profissional. É na busca pela resposta a esses problemas, emergentes no cotidiano escolar e individual de cada sala de aula, ou frente a cada conteúdo, que se dedica o professor. Assim, "a reflexão sobre o conhecimento prático está apoiada em elementos teóricos que, unidos à experiência, [podem] levar o professor a analisar e questionar a sua prática e elaborar estratégias de mudança que legitimem esse conhecimento" (ARRIGO; LORENCINI JR.; BROIETTI, 2017, p. 3).

Três são os processos reflexivos apontados por Schön que podem contribuir para a reflexão docente: a reflexão-na-ação, a reflexão sobre a ação e a reflexão sobre a reflexãona-ação. O processo de reflexão-na-ação, especificamente, caracteriza-se pelo que chamou de "uma sequência de 'momentos'" (SCHÖN, 2000, p. 33), a saber: Momento 1- Zona de Conforto: corresponde às situações de ensino-aprendizagem em que o professor faz uso de respostas espontâneas e rotineiras, pois reconhece que a ocasião encontra-se dentro de certos limites que considera confortável, assim, as ações neste momento são as usuais em sua prática docente; Momento 2- Alerta: ocorre quando uma dada situação desencadeia um resultado inesperado e que sai dos padrões cotidianos, o que faz com que o professor fique atento ao ser surpreendido. Essa surpresa pode ser agradável ou desagradável; Momento 3- Estruturação: corresponde a reflexão no ato da situação, nem sempre acompanhada de verbalização, mas que direciona o pensamento docente a aquilo que o surpreendeu e o porquê o fez; Momento 4- Questionamento: na sequência, a reflexão se volta ao questionamento crítico da situação e de si próprio; Momento 5- Reestruturação: novas estratégias de ação são planejadas ou mesmo à compreensão dos fenômenos é alterada e resignificada; Momento 6- Planejamento da Ação: por fim, a reflexão acarreta em uma ação corretiva que pode ou não responder ao fenômeno, levando, em caso negativo, 
a novas surpresas que exigirão nossas reflexões, reiniciando o ciclo (SCHÖN, 2000; ARRIGO; LORENCINI JR.; BROIETTI, 2017).

Diferentemente, a reflexão sobre a ação é retrospectiva permitindo a reflexão sobre a reflexão-na-ação. Arrigo, Lorencini Jr. e Broietti (2017) complementam que a reflexão sobre a reflexão-na-ação conduz obrigatoriamente à expressão verbal. Assim, "minha reflexão presente sobre minha reflexão-na-ação anterior dá início a um diálogo de pensar e fazer" (SCHÖN, 2000, p. 36) resultando na melhora do meu eu professor.

Isso consigna na importância de oportunizar ao professor em formação inicial ou continuada um espaço tranquilo para que ele possa repensar em suas ações e ter a oportunidade de expressá-las por meio das palavras, organizando assim seu pensamento em relação ao fenômeno ocorrido, mesmo em situações simuladas.

\section{Procedimentos metodológicos}

Os dados que são expostos à análise no presente artigo foram constituídos durante pesquisa de doutorado, especificamente durante a segunda etapa da coleta de dados na qual foi realizado um Curso de Formação Continuada, oferecido a professores de Ciências e Biologia da Educação Básica por meio de um projeto extensionista em parceria com a Superintendência Estadual de Educação (SEE) do município de Uberaba-Minas Gerais. Participaram do curso, a princípio, um total de 13 sujeitos, sendo 11 professores atuantes, um deles de Química e os demais das disciplinas de Ciências e Biologia, uma professora recémformada e uma estudante de licenciatura, ambas de Ciências Biológicas, alguns deles (Ivan e Cleo) aparecerem nos trechos analisados aqui, tendo nomes fictícios. $O$ curso foi realizado em 8 encontros com duração de quatro horas cada. Em cada encontro, uma temática foi discutida e atividades práticas, simulações e investigações foram realizadas assim como discussões acerca de como inserir o conteúdo Sistemática Filogenética na prática de ensino.

No último encontro uma proposta de aula construída foi apresentada a partir do comando: Como você trabalharia a classificação biológica com sua turma? Todos os momentos do curso de formação foram gravados em áudio e transcritos na íntegra.

São apresentados e discutidos aqui, trechos selecionados da autoscopia de uma das participantes, Paula ${ }^{3}$, realizada posteriormente à simulação de sua proposta de aula no curso. A aula de Paula constituiu-se de duas etapas. Na primeira, a professora insere um jogo didático cujas regras são similares às do dominó e as peças contêm conceitos e definições para a aprendizagem da forma de reprodução dos grandes grupos vegetais na Botânica (Biófitas, Pteridófitas, Gimnospermas e Angiospermas). Após terem jogado uma partida, os participantes do curso são inseridos na segunda etapa da aula por meio de uma atividade prática para identificação desses grupos botânicos a partir de características básicas, como: embrião, vasos condutores, sementes, flores e frutos. A sequência dessa atividade destinou-se a representação da evolução dos grupos vegetais mediante o método sistemático filogenético em um cladograma.

A organização do ensino da professora constituiu-se não apenas em uma resposta ao comando Como você trabalharia a classificação biológica com sua turma?, mas também em

\footnotetext{
${ }^{3}$ Ressaltamos que todos os nomes dos participantes da pesquisa são fictícios.
} 
uma intencionalidade de propiciar aos alunos do Ensino Médio, conforme seu plano de aula, o conhecimento acerca de como construir um cladograma e não apenas interpretá-lo já pronto, como aparece em livros didáticos. Essas reflexões emergem em sua fala, analisada na sequência que refletem ainda a aprendizagem possibilitada pelo curso de formação continuada.

Portanto, os discursos de Paula submetidos à análise são posteriores à sua aula e rementem a ações durante a aula simulada embora também se reportem ao momento do planejamento desta, que foi individual da participante em sua casa e durante o qual os professores formadores do curso não tiveram participação. Assim, neste trabalho, buscamos identificar por meio da autoscopia indícios dos tipos de reflexão caracterizados por Shön (2000).

\section{Análises e discussões}

Ao inserir os participantes do curso (que simulavam os alunos em sua aula) no jogo de dominó sobre a reprodução dos vegetais, Paula procurava reforçar os conhecimentos sobre as características que distinguem os grandes grupos botânicos, uma vez que elas seriam mobilizadas na tarefa prática seguinte. Essa ação indica que na organização do ensino da professora as características do Reino Plantae já teriam sido trabalhadas em aula anterior. Por isso a segunda etapa de sua aula destina-se a minuciosamente aplicar o método sistemático filogenético para transformar essas principais características em uma representação evolutiva, o cladograma. Esta etapa demanda domínio dos aspectos de ensino-aprendizagem da professora, de modo que suas reflexões estão inseridas na relação professor, aluno e conteúdo de ensino. É durante a simulação da aula que a primeira situação desencadeadora da reflexão de Paula aparece como forma de alerta.

Na explicação, a professora dispõe as características principais dos quatro grupos vegetais que denominou por letras do alfabeto (A-Briófitas, B-Pteridófitas, CGimnospermas e D- Angiospermas) em um quadro denominado de matriz filogenética. Para isso, utiliza o sistema binário: zero (0) para apontar as características ausentes no grupo e um (1) quando determinadas características estão presentes no grupo, conforme o método sistemático filogenético é ensinado por Amorim (2000). Os alertas, visualizados neste trecho, correspondem à forma ou didática com que conduziu a explicação.

Paula: [...] gimnosperma a gente sabe que a semente é nua, não tem fru... é... não tem fruto. Vou pôr zero, e aqui, 1 ((escrevendo no quadro)). Flores e frutos. Briófita é tudo falso, então a gente sabe que não tem. Pteridófita, ela é folha, não tem flor e nem fruto. Gimnosperma não tem flor, mas tem semente, mas aqui a característica que a gente tá olhando é flor e fruto. E aqui, angio, que a gente tem. Aí o próximo passo então... é a gente colocar aqui o A, B, C e D, e, analisar a matriz filogenética. Aqui... se... primeira... no primeiro grupo: Briófita, Pteridófita, Gimnosperma e Angiosperma, nessa coluna a gente viu que o grupo B, C e D compartilham a... a... essa característica.

Professora Formadora: Professora, da onde saiu B, C e D lá?

Paula: Ah, B, C e D que a gente aqui identificou no começo da lição, os grupos.

Professora Formadora: Ah tá, é verdade. 
Paula: E aqui a gente vai... eu vou denominar, que eu esqueci de pôr durante aqui no quadro, que vai ser a característica... Ah! Aqui na folha tem. Presença de... Embaixo tem. Presença de sistema vascular é 1. É... folhas e caules verdadeiros, quem compartilha aqui? Pteridófita, Gimnosperma e Angio. Então... eu vou colocar 2 aqui também.

Neste trecho da aula simulada, observamos os dois primeiros momentos de Alerta de Paula. Alerta 1: quando a professora formadora do curso questiona a origem das letras na representação efetuada por Paula. Uma pergunta cabível de ocorrer em situações de ensino reais, onde para o professor a lógica demonstrada está clara, mas o aluno nem sempre a percebe. Paula, embora tenha uma resposta confortável sobre a situação, pondera no momento seguinte sobre algo que deixou de explicar aos alunos. Assim, o Alerta 1 serviu como um alerta seguinte, antecipando sua ação. $O$ interessante é perceber neste trecho da cena que Paula verbaliza seu questionamento, algo não tão comum durante uma reflexãona-ação, consistindo em seu Alerta 2: "eu vou denominar, que eu esqueci de pôr durante aqui no quadro, que vai ser a característica... Ah! Aqui na folha tem". É como se estivesse falando consigo mesma, assumindo o esquecimento e corrigindo para que outros alunos não façam o mesmo questionamento da professora formadora: da onde saiu essas características?

Tendo levantado as características expostas na folha de atividade entregue aos alunos, Paula conduz a construção da árvore filogenética, e mais um alerta surge:

Paula: [...] Agora vamos tentar montar o nosso... nosso cladograma ou árvore filogenética. [...] eu já vou explicando como é que a gente monta. Então, aqui a gente tem um ancestral. Qual que é o grupo que surgiu primeiro? Durante... que a gente viu durante o que foi explicado? A gente tem o grupo A que é isolado certo? Se for parar pra pensar. Ele não compartilha as outras características com os outros grupos ele é bem diferente. Então a gente fala que aqui tinha um ancestral que deu origem ao grupo A. Depois, olhando aqui, a gente tem os grupos B, C e D que compartilham as características. Que, quais são? Folhas e caules verdadeiros. Então aqui vai surgir o passo 1. Ah, não, mentira... passo... passo 1. Depois pra seguir a gente tem o grupo C e D que compartilha... aqui ó, sistema vascular então todos compartilham. Depois folhas e caules verdadeiros todos os grupos aqui também compartilham. $\mathrm{O}$ grupo $\mathrm{C}$ e $\mathrm{O}$ D, Gimnosperma e Angiosperma compartilham... aí surgiu o grupo B que é Pteridófita. Aí surgiu outra característica, a propagação de sementes, que aí através de várias adaptações, evoluções, surgiu o grupo $C$ que é Gimnosperma que a gente falou lá do pinhão. Depois surgiu mais uma caraterística que foi o fruto aqui... a semente ser protegida por frutos. E depois, uma outra evolução que foi é... flores e fruto aí surgiu um grupo de angiosperma. Isso aqui aconteceu... ((Fig. 1)).

Professora Formadora: Professora?

Paula: Pode perguntar.

Professora Formadora: Como... como que eu sei que fica assim? Da onde a senhora tirou essa estrutura?

Ivan: Sequência.

Professora Formadora: Por que que é assim? Eu não posso colocar só $A$, $B, C$ e $D, 1,2,3,4,5$ ? Por que que eu sei que é assim? 
Paula: Então, existe... essa é uma forma de representar. Existe é... a gente abordou um tempo atrás sobre quem, como que foi feita a taxonomia e as representações. Durante o estudo, foi visto que isso é tipo uma linha do tempo e que cada marcação denota então um passo evolutivo.

Ivan: Essa é uma pergunta difícil.

Paula: É.

Ivan: Essa é uma escala de tempo que dois aconteceram em tempo diferente?

Paula: Não. Isso aqui levou milhares de anos.

Ivan: Porque ...

Paula: Essa é uma forma de representar.

Cleo: É difícil explicar isso.

Paula: Foi a primeira... primeiro acontecimento. Pode ser, por exemplo, presença do sistema vascular, então pode ser que as plantas precisavam ter um porte maior, então aí surgiu o sistema vascular. Um grupo foi desenvolvendo, desenvolvendo e aí aconteceu esse acontecimento. Surgiu essa adaptação, depois outra adaptação. Então os grupos de plantas foram... foram se adaptando. Modificando conforme o ambiente, conforme o passar do tempo e a sua necessidade. E assim chegamos até o grupo atual que sofreu mais adaptações que é a angiosperma que é o mais populoso.

O Alerta 3 de Paula surge quando é questionada acerca da metodologia da sistemática filogenética.

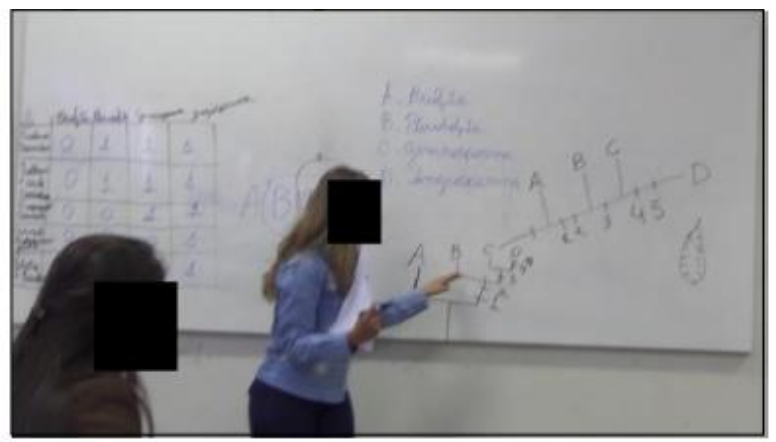

Figura 1: Árvore Filogenética das Plantas na aula de Paula. Fonte: KLEPKA (2017, p. 271).

Paula dá indícios de que a origem da estrutura da árvore filogenética não é compreendida por ela própria. Em outras palavras, a teoria que permite que os seres vivos sejam representados daquela forma e não de outra não é de seu conhecimento, isso porque ao ser questionada em vários momentos limita-se a responder: "essa é uma forma de representar". Entretanto, durante a ação a professora não demonstra verbalmente refletir sobre a ação em si. Esse momento poderia ser identificado como de Estruturação que embora possa tê-la direcionado o pensamento sobre aquilo que a surpreendeu não a levou a agir. De modo que Paula apenas concorda com os colegas acerca da dificuldade de explicar, e planeja uma saída para não ficar sem resposta, mas que foge do que foi questionado pelo aluno. Assim, Paula encontra-se frente a um alerta desconfortável, sobre o qual posteriormente reflete em sua autoscopia, sem mesmo ser questionada:

Eu deixei ela mais pro meio, a sistemática filogenética, porque estou meio insegura. Durante a apresentação eu acho que deu pra ver isso. Em 
algumas coisas eu ainda tenho insegurança pra eu trabalhar. A matriz, eu olhava, eu refiz uma colinha pra... pra saber. Porque foi uma coisa bem recente eu nunca tinha... e a representação eu fiz em casa, eu olhei, eu li o material todinho que vocês me forneceram pra ter uma confiança em trabalhar $^{4}$ (Paula, em autoscopia).

Neste caso, a reflexão ocorreu sobre a ação. Já que no trecho da aula não há indícios de ter havido qualquer reflexão ali, muito embora seja possível que a professora tenha percebido e apenas seguido em frente com a aula. Dessa forma, Paula assume sua insegurança, ao mesmo tempo em que nas entrelinhas de seu discurso percebemos que entende a necessidade de estudar mais a respeito, já que se trata de um conteúdo novo para ela.

A aula de Paula, também chama atenção pelo descompasso entre o planejamento, observado pelo plano de aula entregue, e sua execução. A professora diz aos alunos que trabalhará com os reinos, iniciando pelo plantae. Entretanto, ao propor uma aula prática mediante um jogo (sobre as características das plantas) para fixar o conteúdo, subentendese que esse reino já foi trabalhado em uma aula anterior. Posteriormente ao jogo é que seu planejamento se efetiva, como que se lembrasse que deveria incluir a sistemática filogenética, e então, menciona rapidamente que "na aula passada, a gente viu sobre como construir uma matriz éh...éh... matriz filogenética e também cladograma", voltando a mencionar o aspecto filogenético apenas para definir que há quatro grupos, parando por aí quanto a este método. Questionada do por que escolheu trabalhar com ambas as classificações, Paula demonstra que seu planejamento estava permeado pela dúvida sobre qual das propostas classificatórias usar: "Éh:: e eu fiquei pensando, éh:: eu trabalho Lineu? Eu trabalho a questão filogenética?".

Tal reflexão pode ser explicada de duas formas: Paula considera importante o trabalho com as características propiciadas pela ênfase nas categorias dos reinos, por meio da tradicional classificação que o ensino de ciências reconhece como Lineano, o que se confirma com sua opção pelo uso de um jogo para fixação das características. Portanto, seu uso reflete uma prática de anos de aprendizado e de docência. Contudo, ao mesmo tempo, admite a deficiência dessa abordagem, atribuindo isso ao livro didático e justificando o necessário uso da árvore filogenética em sua aula, o que pode ser um reflexo do curso de formação continuada.

É interessante também observar a reflexão que Paula faz durante a autoscopia no que diz respeito às suas reflexões durante seu planejamento pessoal e que, de alguma forma, definiu sua aula, minimizando possíveis alertas. É no planejamento que os momentos de reflexão-na-ação destacados por Schön (2000) são mais evidentes. Desse modo consideramos que neste momento a ação sobre a qual Paula detém-se a refletir, retrospectivamente, é sobre a de planejamento.

Na sequência de suas ideias o primeiro momento percebido é o de Alerta, ocasionado pela constatação da deficiência do livro didático com relação ao conteúdo de sistemática filogenética:

\footnotetext{
${ }^{4}$ Material disponibilizado pelo Curso de Formação Continuada (KLEPKA, 2017).
} 
[...] o livro didático, ele traz uma abordagem muito simples do... de como evoluiu ((os seres vivos)). Ás vezes não tem essa... essa representação, está no livro em um exercício, só que aparece lá difuso entendeu? Jogado. Não tem nada explicando como surgiu essa... essa árvore filogenética, esse cladograma (ALERTA).

Posteriormente, o alerta leva-a a estruturar seu pensamento e o porquê the incomodou: "a matriz eu não tinha visto até então e é uma coisa importante, um método pra gente chegar até a árvore filogenética". Justificando a reflexão do momento seguinte: "Então eu trouxe um histórico, uma metodologia. Por isso que eu quis trabalhar". Esse momento é uma resposta verbal a um pensamento que não foi verbalizado na autoscopia, mas que poderia ser traduzido como se Paula se questionasse: por que eu quis trabalhar a árvore filogenética? E o questionamento continua no trecho seguinte levando ao segundo alerta em seu planejamento. "E é importante. Por quê? O professor geralmente trabalha [...] cada aula, um tema. Como que o aluno... Eu tenho dificuldade, eu tenho que fazer relações, então tudo pra mim tem que ter uma historinha".

Ao reconhecer a si própria como um sujeito em aprendizagem, Paula adota a visão do outro. É essa alteridade que faz a professora chegar ao momento seguinte da reflexão, segundo Schön (2000), no qual reestrutura em seu pensamento acerca do por que uma árvore filogenética é mais condizente com uma explicativa evolutiva do que uma simples separação de características estanques em grupos.

Então, quer dizer que surgiu primeiro briófita, depois de milhares de anos aconteceu um monte de passos de eventos, depois veio o que sofreu novas adaptações. Então, eu sempre gostei de ver o grupo intermediário. O que deu origem. Como foi? E tem que ter ligação. Senão o aluno vai falar: então quer dizer que a briófita não é importante? Ah, quer dizer que a angiosperma é a melhor? Não, não é. Tem que ter um sentido (REESTRUTURAÇÃO).

Paula percebe o que a levou a planejar o jogo: "E assim, o jogo veio pra fixar as características". Esse momento leva a professora a refletir sobre a reflexão-na-ação, momento no qual percebeu com surpresa a eficiência do jogo, o novo Alerta:

Porque o aluno não joga só uma vez, ele sempre se empolga e joga 2, 3, 4 vezes. Muda de grupo. Ah não, vamos trocar? E acaba que ele fixa as características do grupo, que são difíceis. Eu escutei vocês falando: nossa mais, arqueogônio... é tubo austorial... Como que o aluno vai fixar aquilo se ele viu uma vez? (ALERTA)

O alerta ocorrido remete a Paula novamente o deslocamento da reflexão sobre a ação simulada para a ação de planejamento, suscitando nela nova estruturação: "O jogo é pra isso, uma maneira didática, lúdica... eu gravei através disso, construindo esse jogo. Muita coisa eu aprendi construindo o jogo porque durante a aula é muito...". Que seguiu para o questionamento e a reestruturação que a levou efetivamente a adotar o jogo como estratégia de ensino: "[...] Então eu acho importante trabalhar, eu sempre gosto de trabalhar teoria e alguma coisa pra fixar. Uma atividade lúdica ou mesclo com atividade prática pra depois introduzir, ou uma atividade que...".

Embora não tenhamos participado do planejamento de Paula, é possível perceber por seu relato durante a reflexão posterior a sua aula simulada que houve momentos de 
reflexão durante o planejamento que certamente conduziram sua ação, antecipando situações e, mais que isso, possibilitando uma visão de alteridade, sobre como o outro compreende e poderia compreender. Arrigo, Lorencini Jr. e Broietti (2017) chamam essas reflexões que ocorrem durante o planejamento de uma situação de ensino como reflexões para a ação, mais especificamente reflexões sobre a reflexão para ação. Foram estas reflexões que deram significado ao que foi aprendido no curso de formação continuada e a levaram a refletir criticamente sobre o papel do conteúdo para o aluno e efetivaram-se na proposição de sua aula: "A matriz dá o sentido, é o fundamental. Como que eu vou montar então essa árvore? Então eu tenho que trabalhar matriz. Gasta um pouquinho de tempo a mais? Gasta, mas eu vou dar sentido a árvore filogenética. Ó o tanto que é mais fácil a gente olhar a matriz e ver...".

Observamos por meio de suas reflexões que, após questionar o seu próprio aprendizado com relação à classificação biológica e a própria forma com que o conteúdo é apresentado no ensino de ciências e biologia, Paula reestruturou suas estratégias para a aula simulada planejando uma ação que, embora não tenha sido tão rica quando os questionamentos críticos que suscitaram seu planejamento fê-la pensar sobre sua prática docente. Notou suas dificuldades em abordar o método sistemático filogenético, embora compreenda sua interpretação. Paula até cita, em sua autoscopia, quais seriam as mudanças necessárias para uma próxima aula sobre o tema, correspondendo a um reconhecimento dos problemas envolvidos em sua prática de ensino: "com certeza eu faria primeiro essa filogenética e depois viria esmiuçando os grupos, dentro da árvore. Focaria toda a aula lá, hoje a gente vai falar do grupo $A, B, C, D^{\prime \prime}$. Isso sugere que o método sistemático permite trabalhar a evolução das características do grupo o que resultaria no abandono do ensino isolado das características vegetais.

\section{Considerações finais}

A análise da autoscopia de Paula, posteriormente à aula simulada, proposta final do Curso de Formação Continuada e, retrospectiva, ao seu próprio planejamento, nos permitiu identificar que houve reflexões-na-ação e, mais significativamente, como chamaram Arrigo, Lorencini Jr. e Broietti (2017), reflexões sobre a reflexão para ação.

Essa reflexão voltada para o planejamento em maior medida do que para a aula simulada em si, pode estar associada à expectativa que o Curso suscitou em Paula, bem como a uma expectativa individual, enquanto docente ao propor uma aula que diferenciasse do ensino tradicional dos grupos vegetais, demonstrando a importância dessa etapa para a professora.

Assim, os pressupostos epistemológicos de Schön (2000) com relação à reflexão na e sobre a prática docente nos permitiram observar as aprendizagens da professora, mas principalmente seu processo de desenvolvimento e suas escolhas ao planejar uma aula, bem como as dificuldades encontradas antes e durante a aula quanto ao conteúdo de sistemática filogenética. 


\section{Referências}

ALARCÃO, I. Ser professor reflexivo. Comunicação. Anais do $8^{\circ}$ Congresso Nacional da Associação Portuguesa de Professores de Inglês. Portugal, 1994.

AMORIM, D. S. Fundamentos de sistemática filogenética. Ribeirão Preto: Holos, 2002.

AMORIM, D.S. Paradigmas pré-evolucionistas, espécies ancestrais e o ensino de zoologia e botânica. Ciência \& Ambiente, n. 36, p. 125-150, 2008.

ARRIGO, V.; LORENCINI JR., A. BROIETTI, F.C.D. A autoscopia bifásica integrada ao microensino: uma estratégia de intervenção reflexiva na formação de professores de química. Investigações em Ensino de Ciências, v. 22, n.1, p. 01-22, 2017.

BRASIL. Decreto no 19.800, de 18 de abril de 1931. Programas do curso fundamental do ensino secundário e instruções metodológicas. Diário Oficial, Rio de Janeiro, RJ, 31 de julho de 1931.

BRASIL. Ministério da Educação. Secretaria da Educação Média e Tecnológica. Parâmetros Curriculares Nacionais + (PCN+) - Ciências da Natureza e suas Tecnologias. Brasília: MEC, 2002.

CORDEIRO, R.S.; MORINI, M.S.C. Historia da filogenia: uma análise dos livros didáticos aprovados pelo PNLD/2015. Revista Científica UMC, v.2, n.2, p.1-15, 2017.

KLEPKA, V. Mudanças históricas e epistemológicas na taxonomia e suas repercussões atuais no ensino de ciências e Biologia. Tese, Doutorado em Educação para a Ciência e a Matemática. Universidade Estadual de Maringá, Maringá, 2017.

LIPORINI, T. Q. O ensino de sistemática e taxonomia biológica no ensino médio da rede estadual no município de São Carlos. Dissertação. 186 f. 2016. Universidade Estadual Paulista. Faculdade de Ciências, Bauru, 2016.

LOPES, W.R.; VASCONCELOS, S.D. Representações e distorções conceituais do conteúdo "filogenia" em livros didáticos de biologia do ensino médio. Revista Ensaio, v. 14, n.3, p. 149165, 2012.

RODARTE, M.F.; SANTOS, F.S. Algumas potencialidades de um curso de formação continuada com o tema ensino de sistemática filogenética para professores ciências e biologia. Anais. $6^{\circ}$ Seminário interno do programa de Pós-Graduação multiunidades em ensino de ciências e matemática - PECIM, Unicamp. 29 a 30 set. p. 73-83, 2016.

RODARTE, M.F.; SANTOS, F.S. Algumas potencialidades de um curso de formação continuada com o tema ensino de sistemática filogenética para professores ciências e biologia. Anais. $6^{\circ}$ Seminário interno do programa de Pós-Graduação multiunidades em ensino de ciências e matemática - PECIM, Unicamp. 29 a 30 set. p. 73-83, 2016.

SADALLA, A. M. F. A.; LAROCCA, P. Autoscopia: um procedimento de pesquisa e de formação. Educação e Pesquisa, v. 30 n.3, p. 419-433, 2004.

SANTOS, C.M.D.; CALOR, A.R. Ensino de biologia evolutiva utilizando a estrutura conceitual da sistemática filogenética-I. Ciência \& Ensino, v.1, n.2, p. 1-8, 2007.

SCHÖN, D. A. Educando o profissional reflexivo: um novo design para o ensino e a

aprendizagem. Tradução de Roberto Cataldo Costa. Porto Alegre, RS: Artmed, 2000. 
SOUZA, S. J. Infância e Linguagem: Bakhtin, Vygotsky e Benjamin. Campinas-SP: Papirus, 1994.

TAKEUCHI, M.R. Livros escolares e ensino de ciências na instrução pública elementar brasileira do século XIX ao XX. Tese. 227f. 2017. Pontifícia Universidade Católica de São Paulo, 2017. 